\title{
Estudios
}

\section{EL LIBRO DEL DEUTERONOMIO, EL CIERRE DEL PENTATEUCO Y EL SURGIMIENTO DE LA IDENTIDAD DE ISRAEL}

Fecha de recepción: 16 de enero de 2019

Fecha de aceptación y versión final: 4 de marzo de 2019

RESUMEN: El Deuteronomio, hoy quinto y último libro del Pentateuco, constituye, en una perspectiva literaria, una colección de discursos puestos en boca de Moisés en la Transjordania, antes de morir y delegar el liderazgo de la entrada en la tierra en manos de Josué. En una aproximación teológica, es un libro fundamental para comprender buena parte de la teología del Antiguo Testamento, porque sintetiza los elementos fundamentales de la fe israelita: ley, alianza, elección y pueblo. Su composición, larga y compleja, permitió a Israel dar forma a una reflexión de identidad que convirtió el texto en uno de los libros religiosos más populares durante el segundo templo, y en la clave para comprender la Escritura como pieza fundamental de la instrucción de Israel. Esta popularidad explica también que ejerciera una influencia notable en el Nuevo Testamento.

PALABRAS CLAVE: Deuteronomio; deuteronómico; deuteronomista; identidad de Israel.

* Catedrático. Facultad de Teología de Granada: junkalguevara@yahoo.es; ORCID: https://orcid.org/0000-0003-1097-1858 


\section{The Book of Deuteronomy, the Closing of the Pentateuch and the Arising of the Israel's Identity}

ABSTRACT: Deuteronomy, the fifth and final book of the Pentateuch, constitutes, in a literary perspective, a collection of discourses put in the mouth of Moses in the Transjordania, before dying and delegating the leadership of the entry into the land in the hands of Joshua. In a theological approach, it is a fundamental book to understand a good part of the Old Testament theology, because it synthesizes the fundamental elements of the Israelite faith: law, alliance, election and people. Its composition, long and complex, allowed Israel to shape an identity reflection that made the text one of the most popular religious books during the second temple period, and the key to understanding Scripture as a fundamental piece of Israel's instruction. This popularity also explains that it exercised a remarkable influence in the New Testament.

KEY WORDS: Deuteronomy; deuteronomic; deuteronomistic; Israel's identity.

\section{INTRODUCCIÓN}

El Deuteronomio es hoy el quinto y último libro del Pentateuco que se ha transmitido a través de la Vulgata con este nombre, que se deriva de la traducción griega de los LXX que en Dt 17,18, donde el texto hebreo dice que el rey «hará escribir una copia de la ley que conserven los sacerdotes levitas» (Dt 17,18), traduce "hará escribir una segunda ley que conserven los sacerdotes levitas».

Pero el sentido común de las palabras de la traducción griega no deja de ser acertado para referirse a este libro de la Biblia que, en realidad, es una colección de leyes dadas por Moisés al pueblo en la llanura de Moab, justo antes del paso del Jordán para entrar en la tierra prometida.

Y, aunque no constituyen una segunda ley, diferente de la anterior, sí se trata de una segunda entrega de la ley que había sido pactada en el monte Sinaí.

Deuteronomio es un libro fundamental para comprender buena parte de la teología del Antiguo Testamento, porque sintetiza los elementos fundamentales de la fe israelita: ley, alianza, elección y pueblo. Fue uno de los textos religiosos más populares durante el segundo templo, y «ha dejado una marca teológica sobre el contenido de la triple división del Antiguo Testamento (Ley, profetas y los demás escritos); y es, después de 
los Salmos, el libro con mayor representación en Qumram (29 veces, por 36 del libro de los Salmos y 21 de Isaías)» ${ }^{1}$.

Su proyección en el Nuevo Testamento es decisiva, como lo muestra el hecho de que sea uno de los libros más citados². «Todas las instrucciones del Deuteronomio colorean la vida y la enseñanza de Jesús de Nazaret: es el primer libro del Antiguo Testamento que cita (después del bautismo, durante las tentaciones en el desierto); utiliza Dt 6,5 como una de las claves de comportamiento para sus discípulos..., y combina este mandamiento con Lv 19,18 para resumir toda la ley y los profetas» ${ }^{3}$.

También Hechos identifica a Jesús con el profeta, "como Moisés», que el Señor tenía que suscitar (Dt 18,15; Hch 3,22-23) y modela la comunidad ideal con imágenes tomadas del quinto libro de Moisés (Hch 4,34; Dt 15,4). Y, por último, es Pablo quien hace un mayor uso del Deuteronomio en sus cartas, por ejemplo, de Dt 30,11-14 en Rom 10,6-10 y del capítulo 32 en Rom 10,19.

\section{ARGUMENTO DE LA OBRA}

El argumento del Deuteronomio narra la llegada del pueblo de Israel a la estepa de Moab, después del largo camino por el desierto. Moisés sabe que no entrará en la tierra prometida y aprovecha su última oportunidad de enseñar al pueblo. Esta enseñanza, que en buena manera adopta la forma literaria de ley, exhorta a los israelitas a hacer memoria de cómo Dios los liberó de la esclavitud de Egipto peleando por ellos; los llevó camino de la tierra de la libertad por medio del desierto, donde hizo una alianza con ellos por la que se convirtieron en pueblo de su propiedad personal; además, a las puertas de esa tierra, Moisés exhorta

\footnotetext{
1 Se encontraron fragmentos del Deuteronomio en siete cuevas, así como en lugares cercanos como Masaada, Muraba'at y Nahal Heber, cfr. Florentino García, "Les manuscrits du Désert de Juda et le Deutéronome" en Studies in Deuteronomy, in Honour of C. J. Labuschagne, dir. Casper J. Labuschagne y Florentino García Martínez, Supplements to Vetus Testamentum 53 (Leiden: Brill, 1994), 63-82; Julie A. Duncan, "Excerpted texts of 'Deuteronomy' at Qumran”, Revue de Qumrân 69 (1997): 43-62.

2 «Al menos 95 veces, frente a las 103 de Génesis, 113 de Éxodo, 35 de levítico y 20 de Números», cfr. Juan Luis de León, Deuteronomio (Bilbao: Desclée de Brouwer 2009), 10.

3 Emilio López, "El libro del Deuteronomio: puerta abierta, perno entre dos mundos”, Reseña Bíblica 96 (2017): 6-7.
} 
a los israelitas para que vuelvan a escuchar y hacer suyas las exigencias de esa alianza, por cuanto constituye la clave para poder vivir felices y prósperos en esa nueva tierra.

El libro comienza así: «Estas son las palabras que Moisés dijo a todo Israel, al otro lado del Jordán [...]. El año cuarenta, el día primero del undécimo mes [de la salida de Egipto], Moisés comunicó a los hijos de Israel todo lo que el Señor le había mandado para ellos» (Dt 1,1.3).

Estas palabras nos dan la pista de uno de los rasgos decisivos del libro; contiene «palabras de un hombre», no directamente de Dios, cuyo nombre, Moisés, además se dice. Por tanto, las palabras y la mediación de Moisés como transmisor de las mismas tienen importancia en el contenido del libro.

De hecho, muy pronto, al comienzo del capítulo 4, Moisés dice al pueblo congregado: «escucha los mandatos y decretos que yo os enseño para que, cumpliéndolos, viváis y entréis a tomar posesión de la tierra que el Señor, Dios de vuestros padres, os va a dar» (Dt 4,1).

Es decir, esas palabras contienen «mandatos y decretos» que se enseñan; no se imponen, al estilo de los «decretos ley» de los Gobiernos; esos mandatos y decretos constituyen el programa formativo de Israel, programa que, bien aprendido, garantiza no solo la entrada en la tierra, sino la vida feliz y próspera en ella; más aún, configurará a Israel como una gran nación «santa e inteligente» (Dt 2,6b) a los ojos de los demás pueblos.

Probablemente por esa razón, y a diferencia de nuestros planteamientos pedagógicos favorables a los curricula formativos abiertos y flexibles, este contenido en el Deuteronomio no se puede tocar; a los israelitas se les advierte: «no añadáis nada a lo que yo os mando ni suprimáis nada; observaréis los preceptos del Señor, vuestro Dios, que yo os mando hoy» (Dt 4,2).

\section{GÉNERO LITERARIO Y ESTRUCTURA}

El Deuteronomio es una colección de discursos puestos en boca de Moisés, aunque su forma actual es consecuencia, como veremos, de un largo proceso de composición.

El género literario dominante es el de la narración, que se inicia con la voz del narrador que rápidamente cede su puesto a Moisés, para volver a recuperar la palabra en el capítulo 31. 
En conjunto, su forma literaria corresponde al clásico discurso de despedida de un personaje importante, que, de algún modo, se insinúa en Dt 1,37 y 3,27-29, aunque, en realidad, no se explicita hasta que en 31,2 él mismo afirma «tengo 120 años, y ya no puedo salir ni entrar», en clara referencia a Gn 6,3 donde, después del diluvio, se dice: «Mi espíritu no durará por siempre en el hombre, porque es carne; sólo vivirá ciento veinte años ${ }^{4}$. Con todo, esta afirmación contrasta con la del narrador que afirma que murió «habiendo conservado hasta su muerte buena vista y buena salud» (Dt 34,7).

Según Weinfeld ${ }^{5}$ tenemos aquí un reflejo de la tradición sapiencial egipcia, en la que el faraón o un visir, antes de morir, entregan su testamento al sucesor. Por otra parte, tanto en la historiografía bíblica (Jacob, Gn 48,1-18; Josué, Jos 23 y 24; Jesús, Jn 14-17; Pablo, Hch 20), como en la griega, es frecuente poner en boca de los principales protagonistas un discurso de despedida. Ahora bien, lo que no suele ser tan habitual es encontrar, como sucede aquí, hasta tres discursos de despedida, acompañados de una variedad tan notable de materiales como los que encontramos en este libro.

Para algunos estudiosos el libro del Deuteronomio sigue el patrón de una celebración litúrgica de culto donde se hacía la renovación de la alianza. Más tarde, otros especialistas en el asunto constatan que el esquema del libro es muy semejante a los tratados de vasallaje del Cercano Oriente y que, con certeza, en el tiempo de Ezequías y de Josías, los escribas deuteronomistas de la corte usan ese esquema para trabajar los textos del Deuteronomio que habían llegado a sus manos. Las investigaciones recientes acentúan la importancia del texto como producto final de un desarrollo de la religión de Israel en el marco de importantes cambios histórico-sociales.

4 «En realidad, de su muerte no se habla hasta Dt 31-34, aunque, de algún modo, se insinúa en Dt 1,37 y 3,27-29. La referencia a la edad de Moisés, 120 años que conecta con Gn 6,3, va directamente asociada a su muerte e indirectamente está referida en 31,2. Su apreciación contrasta con la del narrador que en 34, sostiene que no se había debilitado su vigor», cfr. Félix García, "La muerte de Moisés, la sucesión de Josué y la Escritura de la Tôrah (Dt 31-34)" en The future of the Deuteronomistic History, dir. Thomas Römer, Bibliotheca Ephemeridum Theologicarum Lovaniensium 147 (Leuven: Peeters, 2000), 86-87.

5 Moshe Weinfeld, Deuteronomy and the Deuteronomic School (Winona Lake: Eisenbrauns, 1992), 261. 
Como sucede generalmente en el estudio de las obras literarias, y desde luego de los textos bíblicos, no faltan hipótesis bien dispares que intentan explicar la composición del Deuteronomio.

$\mathrm{Si}$ atendemos a las fórmulas introductorias que se van repitiendo a lo largo del libro, este se estructura en tres discursos, con una introducción y un epílogo, todos ellos atribuidos a Moisés, que toman esta forma ${ }^{6}$ :
Dt $1,1-5$
Introducción
Dt $1,6-4,43$
Primer discurso
Dt $4,44-49$
Introducción
Dt $5,1-28,68$
Segundo discurso
Dt $28,69-30,20$
Tercer discurso
Dt $31,1-34,12$
Epílogo: Últimos días de Moisés

Por otra parte, si tomamos como referencia el contenido teológico, podemos reconocer una estructura «concéntrica ${ }^{7}$ que queda como sigue:

\begin{tabular}{|l|l|l|l|l|}
\hline $1-3$ & \multicolumn{2}{|l|}{ Narrativa (vinculada con el libro de los Números) } & Redacción final \\
\hline & 4 & \multicolumn{2}{|l|}{ Exhortativa } & $\begin{array}{l}\text { Durante el periodo } \\
\text { del exilio }\end{array}$ \\
\hline & & $5-28$ & $\begin{array}{l}\text { Código deuteronómico } \\
\text { Corazón de la ley }\end{array}$ & $\begin{array}{l}\text { La parte más } \\
\text { antigua del libro }\end{array}$ \\
\hline & $29-30$ & Exhortativa & $\begin{array}{l}\text { Durante el periodo } \\
\text { del exilio }\end{array}$ \\
\hline $31-34$ & Narrativa (vinculada con el libro de Josué) & Redacción final \\
\hline
\end{tabular}

6 Un análisis detallado de la estructura que pasa por la identificación de las formas literarias básicas lo encontramos en Pablo Díaz Herrera, "Deuteronomio: narración o discurso. La forma y la estructura del libro”, Reseña Bíblica 96 (2007): 13-21.

7 Carlos Granados, Deuteronomio (Madrid: Biblioteca de Autores Cristianos, 2017), xxviii. 
Así, el centro y, por tanto, la clave fundamental del libro del Deuteronomio la encontramos en el llamado «Código Deuteronómico»; es aquí donde podemos identificar esa «teología sionista» a la que se refiere Römer y que estaría marcada por tres ideas principales: el monoyavismo, la centralización del culto y de la justicia.

\section{EL PROCESO DE COMPOSICIÓN}

Si hay un apartado complejo en el conjunto de los estudios del Deuteronomio, este es, sin duda, el que tiene que ver con el proceso de composición del mismo; es complejo secuenciar en el tiempo en el que comienza y termina la composición del libro; y es casi imposible determinar los sucesivos estratos redaccionales.

De hecho, existe una diferencia entre los autores norteamericanos e israelíes, y los centroeuropeos (particularmente, alemanes) a propósito de cómo y cuándo va desarrollándose ese proceso.

Efectivamente, como muestra P. Altmann ${ }^{8}$, los autores norteamericanos e israelíes, bastante escépticos en lo relativo a la posibilidad de detectar los sucesivos estratos redaccionales, son más partidarios de defender que existe básicamente una redacción preexílica del conjunto; los otros, sin embargo, más inclinados a la redacción tardía del conjunto, creen poder detectar los sucesivos trabajos redaccionales que se producen, probablemente desde el tiempo de Ezequías y hasta la redacción sacerdotal.

En todo caso, y como apuntábamos, el Deuteronomio es el resultado de un largo proceso de composición que, sin embargo, tiene en su forma final una sorprendente unidad, que se advierte no solo en su estilo perfectamente reconocible, lleno de exhortaciones a la fidelidad, de vehementes advertencias contra la apostasía y de repetidas referencias a la pérdida de la tierra, sino también en el acento de ciertas afirmaciones teológicas: el monoyavismo y la monolatría; la radicalidad de la iconoclastia; la preocupación por la transgresiones en materia religiosa; y la consideración del pueblo de Dios como una comunidad de hermanos.

\footnotetext{
8 Peter Altmann, Festive Meals in Ancient Israel Deuteronomy's Identity Politics in Their Ancient Near Eastern Context (Berlin: W. De Gruyter, 2011), 11-16.
} 
Más allá de la existencia de algunas tesis más "conservadoras» ${ }^{9}$, que postulan la autoría mosaica ${ }^{10} \mathrm{o}$, cuando menos, prejosiánica del Deuteronomio $^{11}$, existe hoy un cierto consenso entre los autores a la hora de afirmar que el texto que tenemos hoy en nuestras Biblias es el precipitado final de todo un proceso de composición que comienza en el siglo VIII a. C. y culmina a mediados del IV a. C. ${ }^{12}$.

Los jalones principales de ese largo proceso de composición vienen marcados por la confrontación con los tres grandes imperios que ocuparon Palestina en distintos periodos de su historia ${ }^{13}$, el asirio, el babilonio y el persa, que provocaron en los israelitas una reflexión de tal calado, que convierten al Deuteronomio en «una encrucijada en la que convergen, en cierto modo, las tradiciones del tetrateuco y de Josué-Reyes; se siente el eco de las tradiciones proféticas y sapienciales. De aquí que algunos lo hayan calificado como «centro del Antiguo Testamento» ${ }^{14}$.

9 Peter T. Vogt ofrece una buena síntesis de las posiciones evangélicas más «conservadoras», cfr. Peter T. Vogt, "Deuteronomy: A History of Interpretation and Evangelical Responses" en Sepher Torath Mosheh. Studies in the Composition of Deuteronomy, dir. Daniel I. Block y Richard L. Schultz (Peabody: Hendrickson Publishers, 2017), 22-29; Jean Pierre Sonnet, The Book Within the Book: Writing in Deuteronomy, Biblical Interpretation Series 14 (Leiden: Brill, 1997), 2n2, aunque el autor, refiriéndose a exegetas contemporáneos, los llama neo-conservadores.

10 Muy recomendable la lectura de Bill T. Arnold, "Deuteronomy as the Ipsissima Vox of Moses", Journal of Theological Interpretation 4, n. ${ }^{\circ} 1$ (2010): 53-74.

11 Eugene H. Merrill, Deuteronomy, New American Commentary 4 (Nashville: Broadman \& Holman, 1994), 398-399; Kenneth A. Kitchen, On the Reliability of the Old Testament (Eerdmans: Grand Rapids, 2003), 283-307; Daniel I. Block, "How Many is God? An Investigation into the Meaning of Deuteronomy 6:4-5", Journal of the Evangelical Theological Society 47 (2004): 193-212.

12 «I share the view of scholars generally that Deuteronomy was not written at one sitting, but emerged through various stages of composition and redaction. It is widely agreed that in its present form it derives from the exilic period, with allowance also, however, for some still later, post-exilic additions. Most scholars also agree, though with significant variation in detail, that the book is part of a larger corpus comprising also Joshua-2 Kings and usually described as a 'Deuteronomistic History', and that the authors and redactors of this corpus contributed significantly to the literary growth from earlier to later stages of Deuteronomy itself», cfr. Ernest Nicholson, Deuteronomy and the Judaean Diaspora (Oxford: Oxford University Press, 2004), 53.

13 Por su claridad, seguimos aquí la exposición de Juan Luis de León, Deuteronomio (Bilbao: Desclée de Brouwer, 2009), 25-26.

14 Félix García López, "Deuteronomio 31, el Pentateuco y la Historia Deuteronomista", en Deuteronomy and Deuteronomic Literature. Festschrift C. H. W. Brekelmans, dir. Lust J. Vervenne, Bibliotheca Ephemeridum Theologicarum Lovaniensium 133 (Leuven: Peeters, 1997), 71. 
Esta centralidad le viene del hecho de ser, desde sus orígenes, un libro para definir la identidad judía «más intensamente que cualquier otro libro de la Biblia» ${ }^{15}$.

\subsection{LA COMPOSICIÓN DEL PROTO-DEUTERONOMIO EN LA CRISIS ASIRIA}

La gran reflexión sobre la identidad israelita que encontramos hoy en el Deuteronomio comienza, como hemos dicho, durante el periodo de la crisis asiria.

Los autores se dividen a la hora de decidir el momento concreto en que la reforma se pone en marcha ${ }^{16}$.

A comienzos del s. XIX, W. de Wette ${ }^{17}$ formuló una tesis, presente ya en algunos Padres de la Iglesia ${ }^{18}$, en virtud de la cual identificó el rollo encontrado en las obras de reparación del templo de tiempos de Josías (2Re 22), sobre el que Josías fundamentó su programa de reformas, con lo que él consideró la versión más primitiva del Deuteronomio (Urdeuteronomium) que se correspondería con los capítulos correspondientes al actual segundo discurso: Dt 12-26.

De Wette sostuvo, además, que el texto era un claro producto del s. VII a. C., y no un texto anterior descubierto entonces, y que la atribución mosaica tenía que ver con la necesidad de legitimar la reforma.

15 Eckart Otto, "Anti-Achaemenid propaganda in Deuteronomy" en Homeland and Exile. Biblical and Ancient Near Eastern Studies in Honour of Bustenay Oded, dirs. Gershon Galil, Mark Geller y Alan Millard, Supplements to Vetus Testamentum 130 (Leiden: Brill, 2009), 547; «Israelite identity is by no means the only matter to which the deuteronomic text attends», cfr. Carly Lorraine Crouch, The Making of Israel. Cultural Diversity in the Southern Levant and the Formation of Ethnic Identity in Deuteronomy, Supplements to Vetus Testamentum 162 (Leiden: Leiden, 2016), 114.

16 Hay autores como von Rad que postulan incluso que el origen del Proto-Deuteronomio está en el Reino Norte, vinculado a la teología profética de Oseas.

17 Willheim M. L., Dissertatio critico-exegetica qua Deuteronomium a propribus pentateuchi libris diversum, alius cuiusdam recentioris auctoris opus esse monstratur (Jena, 1805); publicada posteriormente, Beiträge zur Einleitung in das Alte Testament, 2 vols. (Olms: Hildesheim, 1806-7; repr., 1971).

18 «Ancient anticipations of this insight include Jerome» (Commentary to Ezek 1:1 [PL 25, 17]) and Procopius of Gaza (Commentary to 2 Kgs [4 Kingdoms] 21:8 [PG 87, 1200]); cf. John Chrysostom (Matt Hom 9 to Matt 2:23 [PG 57, 130; cf. 180-81]), Theodoret (Questions in 4 Kings [PG 80, 793]), cfr. Frederick. E. Greenspahn, "Deuteronomy and Centralization", Vetus Testamentum, 64, n. ${ }^{\circ} 2$ (2014): 227-228. 
Los estudios de este autor cambiaron el rumbo de la investigación del Deuteronomio y también del conjunto del Pentateuco.

Así, unos años después, J. Wellhausen ${ }^{19}$, que suscribía la tesis del origen josiánico del Deuteronomio, confirmó que el rollo encontrado en el templo solo podía contener el corazón del actual libro (cc. 12-26), que habría sufrido ya desde sus orígenes una serie de ediciones (quizás los cc. 1-4 y 5-11); además, reconoció en la lengua y el estilo del Deuteronomio una de las fuentes, la fuente $\mathrm{D}$, que insertó en su conocida hipótesis documentaria sobre la formación del Pentateuco.

Las tesis de Wellhausen fueron presentadas al mundo angloamericano por S. R. Driver en su comentario al Deuteronomio, en el que compiló una exhaustiva relación del vocabulario y la prosa de la fuente $\mathrm{D}^{20}$, y que asumió las tesis de Wette y Wellhausen sobre el origen del Proto-Deuteronomio.

Por otra parte, en 1872, P. Kleinert ${ }^{21}$ puso de relieve la existencia de un sistema de marcas a lo largo del relato que, no solo destacaban la estructura en discursos, sino que subrayaban la autoría mosaica de los mismos: Dt 1,1 estas son las palabras que Moisés habló; 4,44 esta es la ley promulgó ante los israelitas; 28,69 estas son las palabras de la alianza que Yahvé pidió a Moisés que concertara; 33,1 esta es la bendición con la que Moisés bendijo a los israelitas.

De esta manera, a principios del s. XX existía ya una hipótesis sólida sobre el origen del Deuteronomio.

A mediados del s. XX M. Noth ${ }^{22}$ desarrolla la hipótesis de Wellhausen afirmando que el Deuteronomio habría sido compuesto como pórtico de la historiografía que se inaugura con el libro de Josué y se clausura en 2 Reyes, a la que él llamó «Historia Deuteronomista», por el influjo de este libro en el conjunto, y que se compuso para explicar que el fracaso de la monarquía de Israel y Judá era consecuencia de la idolatría de los israelitas.

19 Julius Wellhausen, Die composition des Hexateuchs und der historischen Bücher des Alten Testaments, 1. ${ }^{\mathrm{a}}$ ed., (Berlin 1876-77).

20 Samuel R. Driver, A critical and exegetical commentary on Deuteronomy (Edinburgh: T \& T Clark, 1896).

21 Paul Kleinert, Das Deuteronomium und der Deuteronomiker: Untersuchungen zur alttestamentlichen Rechts- und Literaturgeschichte (Bielefeld: Velhagen \& Klasing, 1872) 166-68 en Bill T. Arnold, "Deuteronomy as the Ipsissima Vox of Moses", Journal of Theological Interpretation 4, n. ${ }^{\circ} 1$ (2010): 56.

22 Martin Noth, Überlieferungsgeschichtliche Studien I. Die same inden und bearbeitenden Geschichtswerke im Alten Testament (Halle, 1943). 
Para Noth el conjunto era obra de un único autor, un profeta, que muchos de sus contemporáneos identificaron como Jeremías puesto que la teología deuteronomista era fácilmente identificable en sus oráculos. Asimismo, creyó reconocer en Dt 1-4 y 31,1-32,44 unas inserciones deuteronomísticas del periodo monárquico tardío o incluso del exilio, introducidas para dar al Deuteronomio, precisamente, ese carácter de pórtico de la historiografía.

En nuestros días, los autores proclives a la datación en tiempo de Ezequías ${ }^{23}$ subrayan que la fuerza militar, la potencia económica, la rica cultura y su vistoso politeísmo habrían provocado una profunda crisis que pudo poner la fe yavista en peligro. Esa crisis (720 a. C. - 701 a. C.) pudo suscitar una reflexión en Judá en torno a su propia identidad, a la que quiso responder el rey con un programa centralizador fundamentado en la afirmación de la condición única de Jerusalén y habría sentado las bases de una teología sionista ${ }^{24}$ fortalecida por la centralización del culto y la administración de justicia.

23 Ernest Nicholson, "The Centralisation of the Cult In Deuteronomy", Vetus Testamentum 13, n. ${ }^{\circ} 4$ (1963): 380-389; N. Lohfink sostiene que el núcleo inicial del Dt parece un intento de sistematizar las tradiciones más antiguas en un momento tremendamente convulso en el que la identidad y los valores de los israelitas estarían amenazados por la omnipresencia del mundo asirio, cfr. Norbert Lohfink, "Distribution of the Functions of Power: The Laws Concerning Public Offices in Deuteronomy 16:18 - 18:22", en A Song of Power and the Power of Song: Essays on the Book of Deuteronomy, dir. Duane L. Christensen, Sources for Biblical and Theological Study 3 (Winona Lake: Eisenbrauns, 1993). Martin Rose, "Deuteronomio", en Introducción al Antiguo Testamento, ed. Thomas Römer, Jean Daniel Macchi, y Christoph Nihan (Bilbao: Desclée de Brouwer, 2008), 219; cree que es posible que en los materiales predeuteronómicos la cualidad de santuario «elegido» se le confiriera a un templo del reino norte, particularmente a Siquem, y que, en una interpretación actualizadora después de los acontecimientos del 701 a. C., esta centralidad se interpretara como referida a Jerusalén. Richard D. Nelson "A Response To Thomas C. Römer, The So-Called Deuteronomistic History" en "In Conversation with Thomas Römer, The So Called Deuteronomistic History", The Journal of Hebrew Scriptures vol. 9 (2009), en línea http://www.jhsonline.org/Articles/article_119.pdf, consulta 22 de mayo de 2018.

24 Thomas C. Römer cree que es posible que surgiera una teología sionista de gran fuerza simbólica que tratará de responder al momento desde la convicción de ser el verdadero pueblo de Israel, cfr. Thomas C. Römer "Par amour et pour garder le serment fait à vos pères (Dt 7,8) - Les notions de peuple de Yhwh et d'élection dans le livre du Deutéronome et la tradition deutéronomiste", en Vous serez mon peuple et je serai votre Dieu (Ez 36,28): réalisations et promesse, ed. François Lestang Philippe Abadie, Marie-Hélène Robert, y Marc Rastoin (Bruxelles: Lessius, 2016), 113-134. 
Los autores que se inclinan por una datación de la reforma en tiempos de Josías ${ }^{25}$, por su parte, lo hacen destacando el declive en el que se encontró Asiria en esa época como consecuencia de la revuelta de Babilonia en 627. La progresiva desaparición de las estructuras, a través de las cuales Asiria ejerció su poder, hace plausible que fuera Josías quien pusiera en marcha una reorganización de las estructuras político-administrativas de Judá26.

También es posible pensar que el movimiento hacia la reforma surgiese durante el periodo de Ezequías y lo hiciese como una suerte de reacción subversiva que, incluso durante el periodo de Manasés, y quizás por los años de vasallaje a los que sometió a Judá, existiera una especie de «movimiento subterráneo ${ }^{27}$ en el que se hubiera ido fraguando ese movimiento de reformar que cristalizó después en tiempos de Josías.

En definitiva, lo que sí parece plausible es que desde el reinado de Ezequías y hasta el de Josías, y como respuesta a esa crisis, surgiera en Judá ${ }^{28}$ ese Urdeuteronomium, cuyo núcleo fundamental estaría en Dt 1226, y que constituiría una revisión actualizadora del Código de la Alianza que hoy está en Ex 20,24-23,12 y que, sin duda, existía con anterioridad.

Y, así, en su forma actual, el libro insiste en que no se trata de abolir el código de la alianza, "poned en práctica todo lo que el Señor vuestro Dios os ha ordenado, sin desviaros de ello para nada» (Dt 5,32), pero sí de actualizarlo a la luz de los nuevos desafíos; ahora bien, la revisión era de tal calado que no era posible solo hacer pequeñas reformas, sino que

25 Sin que eso signifique aceptar como histórico el relato de 2 Re 22.

26 «Scholars find evidence that Josiah's reign from a relatively early stage became a time of mounting national revival and optimism as the power of Assyria began to crumble, and that Judah's regained sovereignty and a new-found self-confidence among the ruling and leading parties regenerated faith in the promises to the house of David, inspiring hope for a recovery and reconstitution of the Davidic state that would reincorporate the territory of the erstwhile Northern Kingdom», cfr. Ernst Nicholson, Deuteronomy and the Babylonian Diaspora (Oxford University Press: Oxford 2015), 52.

27 [...] «underground movement», cfr. Richard D. Nelson, "A Response to Thomas C. Römer, The So-Called Deuteronomistic History", The Journal of Hebrew Scriptures vol. 9 (2009), en línea http://www.jhsonline.org/Articles/article_119.pdf, consulta 22 de mayo de 2018.

28 «No han faltado autores que han defendido que la primera edición del Proto-Deuteronomio se fraguó en el Reino Norte y, después, tras la caída de Samaría, pasó al Reino Sur. Son hipótesis difíciles de demostrar», cfr. Carlos Granados, Deuteronomio (Biblioteca de Autores Cristianos: Madrid), xxv. 
se requería una nueva compilación que interpretara el conjunto a la luz de los nuevos tiempos.

En todo caso, como hace notar R. Albertz, «en el estado actual de la investigación, en el que no se atisba un consenso unánime sobre el origen literario del Deuteronomio, resulta prácticamente imposible determinar con exactitud cuál era el contenido real del libro en la época de la reforma, es decir, en los años 622-609» ${ }^{29}$.

En la forma actual del libro, ese núcleo se corresponde con una parte fundamental del segundo discurso, está enmarcado entre Dt 4,45 que sirve de introducción, y Dt 28,68 que funcionaría a modo de conclusión ${ }^{30}$.

\subsection{LA REVISIÓN DEUTERONOMISTA DURANTE EL PERIODO BABILONIO}

Durante el periodo neobabilonio, y fundamentalmente desde la caída de Jerusalén, se produce una primera revisión-ampliación de esos materiales que se ha venido en llamar deuteronomista, y que trata de dar respuesta, una vez más, a una crisis; esta vez, a una doble crisis. La primera, en el momento de la derrota, y ante la necesidad de dar una explicación teológica a la pérdida de la ciudad y la dinastía, consolidadas teológicamente en la promesa que hoy recoge 2Sam 7. La segunda, en el exilio, cuando los deportados se ven confrontados con una nueva realidad en la que corren el riesgo de confundirse y diluirse.

La reflexión teológica de la escuela deuteronomista que surge en esta época, no constituye, por tanto, solo la respuesta a una situación de emergencia $^{31}$, sino también la clave para generar una nueva reflexión sobre Dios, el pueblo y la tierra, que permitiera a los israelitas identificarse como un grupo cultural y religioso en la diáspora.

Dicha crisis plantea al teólogo deuteronomista, de entrada, tres interrogantes: ¿acaso los dioses babilonios son más fuertes que Yahvé y protegen al pueblo y a sus gobernantes de un modo que Yahvé no puede

29 Rainer Albertz, Historia de la religión de Israel en los tiempos del Antiguo Testamento, vol. 1, De los comienzos hasta el final de la monarquía (Trotta: Madrid, 1999), 375.

30 Esta distribución de las fases de composición y la estructura literaria la hemos tomado del comentario de Juan Luis de León, Deuteronomio (Desclée de Brouwer: Bilbao, 2009), 24-25.

31 Ernst Nicholson, Deuteronomy and the Babylonian Diaspora (Oxford University Press: Oxford 2015), 51. 
hacerlo?; ¿acaso Yahvé ha abandonado a su pueblo?; o ¿no será que Yahvé ha castigado a su pueblo por haber incumplido la alianza?

Pero, además, la crisis obliga al deuteronomista a proponer un nuevo modelo de culto, una nueva manera de entenderse como pueblo de Yahvé, y una distinta forma de relacionarse con el otro.

En la forma actual del Deuteronomio esa teología deuteronomista puede intuirse, por ejemplo, en las referencias a la apostasía que se incluyen en el segundo discurso; pero la teología deuteronomista está también detrás del discurso inaugural del libro actual (Dt 1,1-4,44), que resume la historia de Israel desde su estancia en el Sinaí hasta su llegada al Pisga, y en el que se recurre a la memoria como instrumento para elevar la experiencia de la historia a categoría normativa para todas las generaciones.

Con esta ampliación, que confiere al Proto-Deuteronomio casi la forma que podemos reconocer hoy en él ${ }^{32}$, el Deuteronomio se convierte en una obra dirigida a los israelitas en situación de diáspora en cualquier momento de su historia ${ }^{33}$; no solo eso, se erige en puerta e inspiración de la historia deuteronomista de Josué-Reyes a la que se incorpora como prólogo.

\subsection{La incorporación al Pentateuco durante la Época Persa}

Por último, con la caída de Babilonia en 539 a. C., se inaugura en Oriente el periodo persa.

El exilio, como tal, ha concluido.

Durante los años de dominio babilonio (589-539 a. C.) la situación de los judíos se ha hecho muy plural; hay quien ha seguido viviendo en Judá, probablemente sin culto en Jerusalén; otros, desplazados a la zona de Benjamín donde los babilonios eligen Mizpá como capital de la provincia, quizás mantienen una cierta actividad cúltica en Betel. Los samaritanos, por su parte, han mantenido su tradición en Siquem... Y no podemos olvidar la existencia de núcleos judíos en Egipto y en Mesopotamia...

\footnotetext{
32 Véase la nota 12.

33 Ernst Nicholson, Deuteronomy and the Babylonian Diaspora (Oxford: Oxford University Press, 2015), 41-73.
} 
Después de que Ciro restaurase la heredad de David, en la provincia persa de Yehud, el Deuteronomio jugará un papel clave para ayudar al pueblo a definir su identidad como pueblo de Yahvé.

Es en este momento cuando el libro adquiere su impronta final; la que hace de él lo que hoy conocemos. Pero no solo eso, muy probablemente sea en este momento cuando se desgaje de la historia deuteronomista y se una al tetrateuco para formar el Pentateuco que tenemos hoy ${ }^{34}$.

Por esta razón, este momento de revisión de los materiales existentes, y de recolocación de la obra, define no solo el futuro del libro, sino ese carácter de «declaración programática de identidad» que lo caracteriza ${ }^{35}$.

Este trabajo final, como no puede ser de otra manera, resulta complejo, y se desarrolla a distintos niveles ${ }^{36}$.

En primer lugar, parece que el conjunto literario recibe ahora una nueva revisión con tintes sacerdotales, que le permite afrontar la crisis de la dispersión, de la desconexión entre los distintos grupos judíos y del descontento por la falta de un liderazgo capaz de gestionar la nueva situación.

Por otra parte, el trabajo literario en el epílogo del libro (Dt 31,134,12 ) aportará algunos elementos decisivos que marcarán no solo la obra en sí, sino su posición en el conjunto de las Escrituras de Israel.

Además, en la redacción del capítulo $34^{37}$ se incluirán, al menos, tres elementos que permitirán incorporar el libro al Tetrateuco y dar al conjunto de los cinco libros una unidad de fondo y de forma: el juramento

34 Christoph Nihan, "The emergence of the Pentateuch as 'Torah", Religion Compass 4, n. ${ }^{\circ} 6$ (2010): 353-364; John J. Collins, The Invention of Judaism: Torah and Jewish Identity from Deuteronomy to Paul, The Taubman lectures in Jewish studies 7 (Berkeley: University of California Press, 2017).

35 Carly Lorraine Crouch, The Making of Israel. Cultural Diversity in the Southern Levant and the Formation of Ethnic Identity in Deuteronomy, Supplements to Vetus Testamentum 162 (Leiden: Brill, 2016).

36 Sorprende la cantidad y la complejidad de las hipótesis sobre la revisión que los materiales deuteronómicos y deuteronomistas reciben en este momento; por reseñar algunas, Federico Giuntoli, Konrad Schmid, The post-priestly Pentateuch: New Perspectives on its Redactional Development and Theological Profiles, Forschungen zum Alten Testament 101 (Tübingen: Mohr Siebeck, 2015).

37 Las discusiones sobre el redactor o la redacción final del Pentateuco, están suficientemente bien abordadas en el trabajo de Konrad Schmid, "The Late Persian Formation of the Torah: Observations on Deuteronomy 34" en Judah and the Judeans in the Fourth Century B. C. E., ed. Oded Lipschits, Gary Knoppers, y Rainer Albertz (Winona Lake: Eisenbrauns, 2007), 236-245. 
hecho a los patriarcas de otorgarles una tierra (Dt 34,4); la afirmación de la condición profética única y peculiar de Moisés (Dt 34,10); y la descripción de la muerte de Moisés a los 120 años (Dt 34,7) no como consecuencia de un castigo, sino como consecuencia de haber llegado a la edad a la que cualquier criatura del tiempo posterior al diluvio ve agotado su tiempo en esta historia.

De esta manera, al final de su azaroso proceso de composición, el Deuteronomio contribuirá a la decisión de editar una Torá, una opción religiosa y política cuyas consecuencias se perciben incluso en nuestros días ${ }^{38}$.

\section{LAS IDEAS TEOLÓGICAS QUE TENEMOS HOY EN LA VERSIÓN FINAL DEL DEUTERONOMIO}

Teniendo en cuenta la complejidad de muchas de las hipótesis que tratan de explicar cuál ha sido el proceso por el cual los materiales de las distintas escuelas (deuteronómica, deuteronomista, sacerdotal...) han ido incorporándose al texto, optaremos por analizar las grandes ideas teológicas que reconocemos en el texto que tenemos hoy en nuestras Biblias y que constituyen, para algunos, una auténtica revolución teológica ${ }^{39}$.

Así, rastrearemos cuatro claves fundamentales de la identidad israelita tal y como aparecen hoy en el Deuteronomio; estas claves son: Dios, el pueblo, la alianza, de la cual es expresión la ley y, por último, el libro.

\subsection{La imagen de Dios}

Como ya hemos visto, básicamente, existe consenso en los autores a la hora de definir los márgenes del Proto-Deuteronomio entre Dt 6 y Dt 28.

El punto focal de la reforma que se apoya en este Proto-Deuteronomio y que nosotros hemos situado entre los reinados de Ezequías y Josías en Judá, se sitúa en la nueva imagen de Dios que ahora se postula y

38 Jean Pierre Sonnet, The Book Within the Book: Writing in Deuteronomy, Biblical Interpretation Series 14 (Leiden: Brill 1997), 213.

39 Moshe Weinfeld, “Deuteronomy's theological revolution”, Bible Review 12, n. ${ }^{\circ}$ 1 (1996): 38-41, 44-45. 
que proyecta también, como no puede ser de otro modo, una imagen de hombre y de pueblo.

Moshe Weinfeld ${ }^{40}$, uno de los autores que más ha estudiado la reforma deuteronómica, explica que la religión de Israel nunca volvió a ser la misma tras la reflexión teológica que hoy encontramos en el segundo discurso de Moisés, porque incorporó cambios fundamentales en las creencias, el culto, los valores y la organización social. Esta reforma, por tanto, no tuvo carácter exclusivamente cultual, sino que fue una reforma integral que supo aprovechar la oportunidad histórica del declive y desaparición del poder asirio.

El cambio teológico fundamental, como ya hemos dicho, es la nueva concepción de la divinidad, que explica todo lo demás. Se produce con la transición de un Dios que se revela como Dios de Abram, Isaac y Jacob (o del pozo, la tormenta...), un Dios que subraya lo inmediato, y la cercanía de su presencia en la vida del pueblo y en la naturaleza, hacia la imagen de un Dios de carácter más abstracto que se venera «en su nombre» y que se revela, sobre todo, a través de la Palabra; un Dios que no vive ya en el templo, sino que solo su nombre es quien reside o llena el santuario $^{41}$; un Dios a quien ya no se ve, pero a quien ahora se escucha (Dt 4,33;5,23).

Aunque existen otros dioses, dioses tutelares de los pueblos del entorno de Israel, porque solo en dos ocasiones, y en textos tardíos $(4,35.39)$ se afirma que «el Señor es el único Dios, y no hay otro fuera de Él» ${ }^{42}$, Yahvé es «Dios de dioses y Señor de señores; grande, fuerte y terrible» (Dt 10,17), y prohíbe con intolerancia, a veces violenta, incluso, la adoración

40 Weinfeld, “Deuteronomy's theological revolution”, 38-41, 44-45.

41 Rainer Albertz considera que esta teología del nombre debió originarse en Betel, en sustitución del arca como garante de la presencia divina, aunque en los textos conservados siempre está asociada a Jerusalén, cfr. Rainer Albertz, Historia de la Religión de Israel en Tiempos del Antiguo Testamento, vol. 1, De los comienzos hasta el final de la monarquía (Madrid: Trotta 1999), 426. Tryggve N. D., Mettinger, sin embargo, cree que esta teología solo pudo originarse a partir del saqueo del templo en 598/597, y habría alcanzado su máximo esplendor con la teología deuteronomista, después de la destrucción de este, cfr. Ronald Ernest Clements, R. Walter, L. Moberly, y J. Gordon McConville, "A dialogue with Gordon McConville on Deuteronomy", Scottish Journal of Theology 56, n. ${ }^{\circ} 4$ (2003): 512.

42 Thomas Römer, "Le probleme du monothéisme biblique", Revue Biblique 124, n. ${ }^{\circ} 1$ (2017): 12-25. 
a otros dioses, porque de Él son «los cielos hasta el último cielo, la tierra y todo cuanto la habita» $(10,14)$.

Frente a un Dios que «descendió al monte Sinaí, a la cumbre del monte» (Ex 19,20), la reforma deuteronómica subraya en Dios la trascendencia y lo abstracto; omite cualquier imagen de Dios descendiendo para hablar a los israelitas y elimina cualquier representación de la corporeidad de Yahvé. Así, en Deuteronomio a Dios no se le ve, se le escucha.

Este cambio caracteriza esta primera teología deuteronómica como una teología de mediación ${ }^{43}$, que cohesiona a la sociedad israelita en torno a la idea de unidad porque solo un Dios, con un único nombre, Yahvé, se revela a Israel: «Escucha Israel, el Señor nuestro Dios, el Señor es uno solo» (Dt 6,4) 44 $^{4}$ este verso enfatiza la unidad de Yahvé que no se despliega más en distintas formas o manifestaciones ${ }^{45}$, y cuyo culto no se puede fraccionar ya en distintos cultos locales.

Esta nueva comprensión de la idea de Dios, que se define ahora por «su Nombre», trae consigo un doble movimiento de desmitologización y secularización ${ }^{46}$.

En virtud de la primera, se afirma que Dios no vive ya en la tierra, en medio de las vicisitudes de Israel; ya no se sienta sobre el propiciatorio del arca y no se representa de manera alguna.

Por la segunda, se desacraliza la visión del mundo y muchas instituciones, hasta entonces de carácter sacral, desaparecen de la vida corriente: la justicia ordinaria se seculariza, «porque se nombrarán jueces y magistrados por tribus, en todas las ciudades que el Señor tu Dios te dé, que juzguen al pueblo con la debida justicia» (Dt 16,18), y las ciudades de refugio, que dejan de tener un espacio donde el presunto homicida pueda refugiarse $(\operatorname{Ex} 21,13)$, son lugares en los que evitar «que se derrame sangre inocente en medio de tu tierra, que te da el Señor, ni recaiga sangre alguna sobre ti» (Dt 19,10); la celebración del sábado, fundada en la memoria de Egipto, adquiere una dimensión social.

\footnotetext{
43 Rainer Albertz, Historia de la Religión de Israel en Tiempos del Antiguo Testamento, vol. 1, De los comienzos hasta el final de la monarquía (Madrid: Trotta 1999), 421.

44 Thomas Römer, The Invention of God (Cambridge: Harvard University Press, 2015), 202-203.

45 Juan Luis de León, Deuteronomio (Bilbao: Desclée de Brouwer 2009), 93.

46 Marvin Huggins, "Secularization in the Centralization of the Cult in Deuteronomy” (Master of Divinity Thesis, Concordia Seminary St. Louis 1969), 59, en línea http://scholar.csl.edu/mdiv/59, consulta 22 de junio de 2018.
} 
Desaparecen también todas las fiestas religiosas vinculadas a los santuarios locales y, con ellas, la presencia del sacrificio ritual de la vida ordinaria de la gente.

Las dos expresiones fundamentales de esta nueva teología son, por tanto, la centralización del culto y la alianza ${ }^{47}$.

\subsubsection{La centralización del culto}

El cambio en la idea de la divinidad produce, como no puede ser de otra manera, un cambio en el modelo del templo ${ }^{48}$.

El elemento fundamental en el que se expresa la reforma deuteronómica en lo relativo al culto es la centralización del santuario donde dicho culto debe celebrarse. Esta centralización constituye una innovación colosal de la fe israelita, frente a la disposición de la ley antigua que disponía que podía tributarse culto a Yahvé «en cualquier lugar donde se conmemore mi nombre» (Ex 20,24).

Esa centralización está definida en el texto así: «buscaréis el lugar que el Señor vuestro Dios eligiere de entre todas las tribus para poner allí su nombre y morar en él, e iréis allí y allí llevaréis vuestros holocaustos y sacrificios de comunión, vuestros diezmos y vuestras contribuciones, vuestros votos y vuestras ofrendas voluntarias, y los primogénitos de vuestro ganado mayor y menor» (Dt 12,5-6).

El texto elige la palabra lugar [maqom], y evita así otros términos más específicos como templo [hekal], casa [bayit] o santuario [miqdas] que son más frecuentes en Éxodo o Levítico, y el adjetivo «elegido» quiere subrayar el carácter único del lugar.

Más allá de interpretaciones sobre la forma o el modo de erigir el lugar, la expresión «hacer poner allí su nombre» significa tomar posesión del lugar ${ }^{49}$.

47 Rainer Albertz, Historia de la Religión de Israel en Tiempos del Antiguo Testamento, vol. 1, De los comienzos hasta el final de la monarquía (Madrid: Trotta 1999), 428.

48 Victor Hurowitz, "From storm God to abstract being: how the deity became more distant from Exodus to Deuteronomy", Bible Review 14, n. 5 (1998): 40-47; Moshe Weinfeld, “Deuteronomy's theological revolution”, Bible Review 12, n. 1 (1996): 38-41, 44-45.

49 Sandra L. Richter, "The Place of the Name in Deuteronomy", Vetus Testamentum 57, n. ${ }^{\circ} 3$ (2007): 342-366. 
Es paradójico, sin embargo, que el libro marque una y otra vez la necesidad de que el culto se celebre en un único lugar, pero nunca se diga cuál es.

Como hemos visto, Yahvé es uno (Dt 6,4) y para Israel el único ${ }^{50}$, porque no puede conjugarse con otros; es uno y el mismo para todo Israel, por lo que quedan abolidos los cultos locales que fraccionan y diluyen la idea de Dios.

Así, las normas de centralización de culto en la perspectiva deuteronómica solo disponen que el culto a Yahvé se tribute en un único santuario, lo que, en opinión de algunos, no significa que fuera un único lugar durante todo el tiempo o que fuera el santuario «central» ${ }^{51}$.

Los elementos propios del culto del santuario israelita también son redefinidos.

El arca, que era el signo de la presencia cúltica de Yahvé, se presenta ahora como el depósito del Decálogo (Dt 10,1ss), porque el único determinante de la presencia de Dios en medio del pueblo es el cumplimiento de los mandamientos.

Además, ahora se convierte en una mera "arca de madera de acacia» (Dt 10,3), sin que se digan cuáles son las medidas, ni tenga revestimiento de oro puro, por dentro y por fuera; sin cenefa de oro, ni anillas de oro, ni varales de oro para transportarla (Ex 25,10-14).

Los sacrificios que pueden ofrecerse a Yahvé, holocaustos, sacrificios de comunión, diezmos, presentes, votos, ofrendas voluntarias y primogénitos del ganado, deben ofrecerse en este lugar.

El sacrificio de animales se realiza en un ambiente de fiesta y regocijo, sin que se muestre visiblemente una relación entre sacrificio y expiación; queda como un mero acto individual que el israelita celebra, normalmente, en el marco de una peregrinación familiar en la que sí se comparte una comida.

La matanza de animales para uso profano se separa del sacrificio; se puede realizar en cualquier lugar y no está ya sujeta a normas de pureza ritual, a no ser la del derramamiento de la sangre sobre la tierra.

$50 \quad$ Rainer Albertz, Historia de la Religión de Israel en Tiempos del Antiguo Testamento, vol. 1, De los comienzos hasta el final de la monarquía (Madrid: Trotta 1999), 386.

51 Gordon J. Wenham, "Deuteronomy and the Central Sanctuary", Tyndalle Bulletin 22 (1971): 103-118. 
El diezmo, en principio, hay que llevarlo al único santuario, pero si ese viaje entraña una verdadera dificultad para el israelita, puede cambiarlo por dinero y hacerlo llegar al único santuario. Además, tiene un efecto de reparación de las desigualdades porque «Cada tres años apartarás todo el diezmo de tu cosecha de ese año y lo depositarás en tus ciudades, y vendrá el levita, que no tiene porción ni heredad como tú, el emigrante, el huérfano y la viuda que viven en tus ciudades, y comerán hasta saciarse, para que el Señor, tu Dios, te bendiga en todas las tareas que emprendas» (Dt 14,28-29).

La celebración de las festividades se pauta ahora en un calendario concreto de fiestas: "Tres veces al año se presentarán los varones al Señor, tu Dios, en el lugar que él elija; por la fiesta de los Ácimos, por la fiesta de las Semanas y por la fiesta de las Tiendas» (Dt 15,16), en la que los varones peregrinan «al lugar que el Señor elija» (Dt 16,15). De esta manera, las fiestas dejan de celebrarse en el marco de la casa familiar, para convertirse en fiestas de peregrinación.

Con estos elementos, los teólogos deuteronómicos habrían pretendido una nueva teología oficial para todo Israel, capaz de cohesionar a los habitantes del reino de Judá para fortalecerse y así conseguir la independencia de un imperio asirio decadente.

La causa por la que la legislación deuteronómica decreta la centralización del culto está totalmente ligada al hecho de la necesidad de purificar el culto a Yahvé52, contaminado en las expresiones populares de elementos propios de las tradiciones cananeas.

Así, la preocupación principal de la reforma será imponer la unidad y el exclusivismo de la religión yahvista. Esta unidad asegurará la identidad de Israel frente a las influencias externas, ahora visibilizadas en el imperio asirio; fundará un sentido de pertenencia a la nación más allá de los avatares históricos; y posibilitará una praxis política que concentrará todo el poder en Jerusalén.

\subsubsection{La alianza}

A la luz de lo que venimos diciendo, se puede comprender que la alianza constituye el tercer rasgo de la identidad de Israel y que el

52 Marvin Huggins, "Secularization in the Centralization of the Cult in Deuteronomy" (Master of Divinity Thesis, Concordia Seminary St. Louis 1969), 59, en línea http:// scholar.csl.edu/mdiv/59, consulta 22 de junio de 2018. 
Deuteronomio aparezca, en la configuración actual del canon, como el documento de la alianza por excelencia ${ }^{53}$.

De hecho, el Deuteronomio acentúa la cuestión de la elección de Israel; del pueblo de Israel, y no del rey $(2 \mathrm{Sam} 6,21)$ o el santuario: «el Señor te eligió para que seas, entre todos los pueblos de la tierra, el pueblo de su propiedad personal» (Dt 7,7).

En el corazón del Deuteronomio, el v. 8 del capítulo 4 se pregunta "¿dónde hay una nación tan grande que tenga unos mandatos y decretos tan justos como toda esa ley que os propongo hoy?» $(4,8)$.

Tomando el esquema de los tratados de vasallaje típicos del oriente antiguo $^{54}$, el Deuteronomio hace memoria de una primera alianza sellada en el Sinaí-Horeb $(5,2-5)$, que ahora se actualiza y renueva en la planicie de Moab, mirando a la novedad que la vida en la tierra introduce precisamente en esa relación de amor expresada en la alianza.

De esta manera, en el conjunto del Pentateuco, estas dos alianzas -en principio- independientes, quedan vinculadas en la forma final porque sellan dos acuerdos entre Israel y Dios al comienzo y al final del itinerario por el desierto.

No solo eso, al tomar el esquema de los tratados de vasallaje (muy particularmente representados en los tratados asirios) y reformularlos, despojando de cualquier autoridad o poder al rey, porque ni el rey asirio ni ningún rey sobre Israel toman parte en la alianza, consiguen una

53 Peter G. Craigie, The Book of Deuteronomy, New International Commentary on the Old Testament (London: Hodder and Stoughton, 1976), 32.

54 Peter T. Vogt hace notar el consenso que existe en torno a la similitud entre la forma literaria de los tratados antiguos del Oriente Próximo y el Deuteronomio. Pero apunta también la teoría de Andrew Mayes que afirma que, a pesar de estas influencias, «de ninguna manera puede considerarse el Deuteronomio un tratado de orden jurídico y que intentar identificar el tiempo de su composición atendiendo precisamente a ese carácter jurídico es inadmisible», cfr Peter T. Vogt, "Deuteronomy: A History of Interpretation and and Evangelical Responses", Sepher Torath Mosheh. Studies in the Composition of Deuteronomy, ed. Daniel. I. Block y Richard L. Schultz (Peabody: Hendrickson Publishers, 2017), 10. La bibliografía sobre esta cuestión es amplísima, cfr. Reinhard Gregor Kratz, "The idea of cultic centralization and its supposed ancient Near Eastern analogies" en One God - One Cult - One Nation, ed. Reinhard G Kratz y Hermann Spieckermann, Beihefte zur Zeitschrift für die alttestamentliche Wissenschaft 405 (Berlin: De Gruyter, 2010), 121-144; Carsten Vang, "The so-called 'Ur-Deuteronomium': some reflections on its content, size and age”, SEE-J Hiphil 6 [http://www.see- j.net/index.php/hiphil/article/view/40] (2009), consulta 1 de septiembre de 2018. 
reinterpretación subversiva de las formas de gobierno propias de la épo$\mathrm{ca}^{55}$, demostrando que la autoridad máxima en Israel la tiene la ley, «que no excede tus fuerzas, ni es inalcanzable porque está muy cerca de ti, la tienes en tu corazón y en tu boca para que lo cumplas» (Dt 30,11-14).

De hecho, el Deuteronomio evita cualquier identificación de Yahvé con el rey, y transfiere la legitimación teológica de los preceptos de la alianza, del rey y su misericordia, a Dios y su compasión ${ }^{56}$.

Esa ley, tan próxima, que exige del israelita una actitud de escucha permanente es también una marca que revela la singularidad de Israel como nación santa y sabia $(4,5)$.

Se comprende así que, a pesar de las discusiones de los estudiosos ${ }^{57}$, podamos afirmar que el término torá elegido para definir la ley de Israel, tiene un sabor sapiencial, que permite comprenderla no como una mera prescripción de obligado cumplimiento, sino como una enseñanza, un modo de vida: Israel «vivirá, crecerá, y el Señor, tu Dios, te bendecirá en la tierra donde vas a entrar para poseerla» (Dt 30,15).

\subsection{LA IMAGEN DEL PUEBLO}

Israel es el pueblo que Yahvé ha elegido $(4,37)$; lo ha elegido por puro amor «de entre las naciones», "cuando el Altísimo daba a cada pueblo su heredad y distribuía a los hijos de Adán trazando el número de las naciones» (Dt 32,8). Por eso, Israel debe su existencia a Dios; es su hijo $(14,1)$, y Dios lo educa y corrige como un padre.

Puesto que el amor de Yahvé es el que lo ha constituido como pueblo: «un pueblo santo; una propiedad personal» $(7,6 ; 14,2)$, él es quien le da unidad, y quien realiza la unión de los distintos miembros de Israel entre sí, de tal modo que Israel aparece descrito, una y otra vez, como una fraternidad.

55 Rainer Albertz, Historia de la Religión de Israel en Tiempos del Antiguo Testamento, vol. 1, De los comienzos hasta el final de la monarquía (Madrid: Trotta 1999), 423.

56 Eckart Otto, Kontinuum und Proprium. Studien zur Sozial- und Rechtsgeschichte des Alten Orients und des Alten Testaments, Orientalia Biblica et Christiana 8 (Wiesbaden: Harrassowitz, 1996), 117-123.

57 Félix García López, "El único pueblo sabio e inteligente: Dios, ley y pueblo en la estrategia religiosa del Deuteronomio (Dt 4,5-8; 6,4-9; 30,15-20)”, Ricerche Storico Bibliche 15, n. ${ }^{\circ} 1$ (2003): 9-24. 
Esta fraternidad se proyecta en las páginas del libro en una doble dirección, vertical y horizontal.

La dirección horizontal de la fraternidad muestra que los israelitas son hermanos (Dt 1,16; 3,18.20; 10,9; 15,3.7.9.11) y, por tanto, iguales e interdependientes ${ }^{58}$. No debe haber pobres entre ellos y si los hay, leyes como el jubileo o el diezmo garantizan la mano tendida de quien ha sido bendecido restaurando la situación del necesitado ${ }^{59}$.

Los colectivos más vulnerables, huérfanos, viudas y levitas, que lo son porque están excluidos de la vida social, tienen oportunidad de participar y ser integrados ${ }^{60}$. Y llama la atención la especial protección que reciben las mujeres esclavas, las prisioneras de guerra, las esposas aborrecidas madres de primogénitos y, como ya hemos dicho, las viudas ${ }^{61}$.

La dimensión vertical de la fraternidad ${ }^{62}$, por su parte, forja la historia del pueblo a través de las sucesivas generaciones, porque las alianzas selladas en el pasado se actualizan en el hoy de la generación que escucha las últimas palabras de Moisés: "No concertó el Señor esta alianza con nuestros padres, sino con nosotros, con todos los que estamos vivos hoy aquí. Cara a cara habló el Señor con vosotros en la montaña, desde el fuego» (Dt 5,3-4).

De esta manera, la memoria actualizada de la alianza sellada entre Yahvé e Israel hace posible el vínculo con los acontecimientos y los protagonistas del pasado, y proyecta el futuro, el de la posesión de la tierra prometida a los padres (Dt 12,1), y el de la constitución de un nuevo pueblo «elevado en gloria, nombre y esplendor, por encima de

\footnotetext{
58 Richard D. Nelson, Deuteronomy: a Commentary, The Old Testament Library (Louisville: Westminster John Knox Press, 2002), 10-12.

59 Patricia Pizzorno, “'No debe haber necesitado en medio de ti...' (Dt 15.4): dimensión social de la bendición en el libro del Deuteronomio", Protestantismo em Revista vol. 23 (2010): 85-91, en línea http://www.periodicos.est.edu.br/index.php/nepp/ article/view/69/125, consulta 16 de septiembre de 2018.

60 Deanna A. Thompson, Deuteronomy: A Theological Commentary on the Bible, Belief: A Theological Commentary on the Bible (Louisville: Westminster John Knox Press, 2014), 13-14.

${ }_{61}$ Haroldo Reimer, "Leyes y relaciones de género - Notas sobre Éxodo 21,2-11 y Deuteronomio 15,12-18”, RIBLA n. ${ }^{\circ} 37$ (2000): 116-127.

62 Susan Haber, "God, Israel and covenant: unity in the Book of Deuteronomy", European Judaism 32, n. ${ }^{\circ} 1$ (1999): 132-141.
} 
todas las naciones que ha hecho; un pueblo santo del Señor tu Dios» (Dt 26,19).

\subsection{El Sefer-ha-Torah: el Libro de La Ley}

Probablemente en los últimos estadios de composición del libro, durante la época persa, se introduce en el Deuteronomio una idea capital que colorea el judaísmo hasta la actualidad; Moisés escribió la ley y ordenó a los sacerdotes y levitas que llevaban el arca, y a los ancianos que cada siete años se realizara una lectura pública de la ley en la que debían congregar a hombres, mujeres, niños y emigrantes (Dt $31,9)$ para que la aprendieran; que la colocaran en el interior del arca, para que se erigiese en testigo de la alianza (Dt 31,25), y para que, si Israel llegaba a tener un rey alguna vez, la leyera todos los días de su vida, aprendiendo a temer al Señor, cumpliendo sus enseñanzas (Dt 17,18-19).

Esta referencia a que Moisés escribió la ley, como en el pasado Dios había escrito la ley, creaba toda una tradición de escritura que, en un futuro inmediato, nada más pasar el Jordán, los israelitas tenían que incorporar, «levantando en el monte Ebal unas piedras grandes y escribiendo en ellas todas las palabras de esta ley» (Dt 27,3).

Así, aunque Moisés no pasara el Jordán sí lo haría el libro y con él una nueva manera de concebir la revelación ${ }^{63}$. En el futuro, Israel escuchará a Yahvé en la palabra escrita de la Torá, que seguirá enseñándose y explicándose por medio de los profetas que «de entre los hermanos, suscitará Yahvé» (Dt 18,15).

La Escritura garantizará, a partir de entonces, que la memoria se perpetúe y quede libre de los acontecimientos que quieran sepultarla o hacerla olvidar; así, la escritura, como expresión de resiliencia ante la crisis y la catástrofe, contribuyó a dar forma a la Torá ${ }^{64}$.

Por tanto, si en el pasado la idolatría constituyó la apostasía más grave de Israel, en el futuro, el único pecado imperdonable será el olvido de la Torá.

${ }^{63}$ Jean Pierre Sonnet, "The Fifth Book of the Pentateuch: Deuteronomy in Its Narrative Dynamic”, Journal of Ancient Judaism 3, n. ${ }^{\circ} 2$ (2012): 213.

64 David M. Carr, Holy Resilience: The Bible's Traumatic Origins (New Haven: Yale University Press, 2014). 


\section{EL DEUTERONOMIO Y EL CIERRE DEL PENTATEUCO}

La incorporación del Deuteronomio, un documento en el que precipitaron a lo largo de la historia de Israel, desde el periodo asirio hasta el persa, las claves fundamentales a partir de las cuales fue definiendo su identidad hacia dentro y hacia fuera ${ }^{65}$, constituye un momento histórico de primera magnitud en la historia del pueblo de Israel.

Como todo final, el cierre del Pentateuco da sentido a todo lo anterior y lo hace resignificando el conjunto de todas las vivencias anteriores ${ }^{66}$.

En primer lugar, el Deuteronomio permite concluir la etapa del desierto y abre el periodo de la conquista-asentamiento en la tierra.

Además, transfiere el liderazgo de la posesión de la tierra a Josué, explicando un nuevo modelo de gobierno inspirado en la imagen de Moisés al frente del pueblo con un doble perfil de legislador y profeta.

En tercer lugar, ordena todo un sistema de instrucción del pueblo y los descendientes ${ }^{67}$, encomendando a los profetas, que expliquen el sentido de la ley; a levitas, sacerdotes y ancianos que exhorten y animen a su cumplimiento; al rey, a que gobierne según sus normas; y al padre de familia a que eduque a sus hijos repitiendo las palabras, en casa, de camino, acostado y levantado; atándoselas en las muñecas y colocándolas en las jambas de las puertas.

Por otra parte, profundiza en la concepción de la religión de Israel y alumbra una nueva economía salvífica, que se convierte en revelación bíblica «del libro» o mejor «con libro» y que apunta lo que luego será el canon de la Escritura ${ }^{68}$.

65 Es interesante notar, como hace Carly Lorraine Crouch, que la reflexión sobre la identidad no se produce solo a partir del exilio y el tiempo posterior, sino que debe considerarse la posibilidad de una reflexión sobre la identidad también en la época preexílica, cfr. Carly Lorraine Crouch, "The threat to Israel's identity in Deuteronomy: Mesopotamian or Levantine?", Zeitschrift für die Alttestamentliche Wissenschaft 124, n. ${ }^{\circ} 4$ (2012): 542.

66 De interesante, aunque no fácil lectura: Frank Kermode, El Sentido de un Fi-

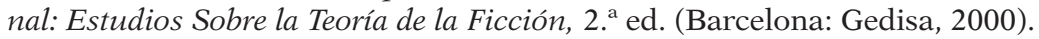

67 Kàre Berge, "Literacy, utopia and memory : is there a public teaching in Deuteronomy?”, The Journal of Hebrew Scriptures 12 (2012), en línea http://www.jhsonline.org/Articles/article_165.pdf, consulta 12 de septiembre de 2018.

68 Jean Pierre Sonnet, "Le Deutéronome et la modernité du livre", Nouvelle Revue Théologique 118, n. 4 (1996): 481-496. 
Así, inaugura un sistema educativo que se despliega en dos ámbitos de aprendizaje: el emocional, cultivado en el marco de la liturgia ${ }^{69}$, y el intelectual, en la enseñanza.

Este sistema educativo, como es propio de una sociedad que se entiende como fraternidad, permite el acceso a la misma a todos los miembros de la comunidad, mujeres, hombres, niños y, también, al emigrante que, de forma temporal, reside en medio del pueblo.

De esta manera, el Deuteronomio fragua un modelo de identidad basado en una ciudadanía ilustrada o como dice Amos Oz, un «linaje de alfabetización $»^{70}$, porque el Pentateuco se convierte, gracias a la incorporación del Deuteronomio, en la base de la educación de todo el periodo del segundo templo, sustituyendo a otros materiales o tradiciones anteriores, como se advierte perfectamente en la literatura de libros como Sabiduría o Sirácida, en la biblioteca de Qumram; en la ideología de saduceos y fariseos y, como hemos visto, en las claves del mensaje y la predicación de Jesús.

\section{EL DEUTERONOMIO EN LA SEPTUAGINTA ${ }^{71}$}

La versión del Deuteronomio que tenemos en Septuaginta es la más próxima a la primera versión del texto, y la fuente más antigua para comprender el Pentateuco, más que el Targum o la Misná ${ }^{72}$.

Como ya vimos, es un texto fundamental durante el periodo del segundo templo, un tiempo en el que Deuteronomio experimentó una notable «expansión " $^{73}$, aunque la mayor parte de las variantes que se perciben en los distintos manuscritos provienen de errores de los copis-

69 El trabajo del profesor P. di Luccio, "La espera de la paz en escritos de judíos y cristianos como ejemplo de definición de identidades", en este mismo número de Estudios Eclesiásticos.

70 Amos Oz y Fania Oz, Los judíos y las palabras (Madrid: Siruela, 2004), 29.

71 Agradezco al profesor J. Chapa que me inspirara la inclusión de este pequeño apartado.

72 John William Wevers, Notes on the Greek Text of Deuteronomy, Septuagint and Cognate Studies / Society of Biblical Literature 39 (Atlanta, GA: Scholars Press, 1995), xiv.

73 Julie Duncan, “Deuteronomy”, en Encyclopedia of the Dead Sea Scrolls, ed. Lawrence H. Schiffman \& James C. VanderKam (Londres Walton Street: Oxford University Press, 2000), 1:199-202. 
tas más que de revisiones o reinterpretaciones del mismo. De hecho, no podemos hablar de tradiciones textuales tan diferentes como las que encontramos, por ejemplo, en Jeremías.

Por regla general, el traductor de LXX se mantiene bastante fiel al texto original, quizás porque el traductor $-y$ los autores están de acuerdo en afirmar que fue uno solo $-^{74}$ era consciente de que traducía un texto sagrado (Carta de Aristeas) y, probablemente, estaba preparando el texto para la lectura en las sinagogas de Alejandría ${ }^{75}$; así, se percibe el interés por hacer el texto comprensible, incluso cuando es posible que el traductor no haya entendido el original correctamente ${ }^{76}$.

El traductor sigue muy de cerca el estilo y la sintaxis del modelo hebreo; el vocabulario denota el uso de un buen griego que ha permitido un trabajo de actualización que se percibe fácilmente, por ejemplo, en la revisión y cambio de nombres propios de personas o lugares...

En el examen del papiro Rylands 458, el más antiguo de los conservados, se advierte que los traductores, judíos bilingües, traducen casi de forma «inconsciente»; con agilidad y sin prejuicios. Sin embargo, una vez que la LXX se convierta en algo visto muy desfavorablemente por los judíos, por el uso que los cristianos hacían de ello, se notará en los copistas que trabajan con otras claves y que, además, no son bilingües ${ }^{77}$.

Con todo, hay innovaciones que tienen interés porque permiten apreciar lo más propio de esta traducción; así, podemos anotar algunos de los cambios:

- En el vocabulario, porque se introducen neologismos o términos más propios de la cultura urbana de Egipto o del mayor nivel de tecnificación ${ }^{78}$.

74 Natalio Fernández Marcos y M. ${ }^{a}$ Victoria Spottorno (dirs.), La Biblia griega Septuaginta, vol. 1, El Pentateuco (Salamanca: Sígueme, 2008), 379.

${ }^{75} \mathrm{~V}$. Tcherikover afirma que el número de judíos en Egipto era realmente grande y que su influjo se hacía sentir en los diversos aspectos de la vida pública del reino; es más, muestra la existencia de Alejandría de un politeuma de los judíos, una autorización oficial para establecerse con ciertas condiciones (exención fiscal, garantías para vivir de acuerdo con sus propias tradiciones y leyes...); cfr. Victor Tcherikover, Hellenistic civilization and the jews (Philadelphia: The Jewish Publication Society of America, 1966).

76 John William Wevers, Notes on the Greek Text of Deuteronomy, Septuagint and Cognate Studies / Society of Biblical Literature 39 (Atlanta, GA: Scholars Press, 1995), xiii.

77 John William Wevers, "The Earliest Witness to the LXX Deuteronomy", Catholic Biblical Quarterly vol. 39 (1977): 233-234.

78 La Bible d'Alexandrie. Le Deutéronome, introduction et notes Cécile Dogniez et Marguerite Harl (Paris: Éditions du Cerf, 1992), 63-67. 
- En las expresiones que denotan distintas comprensiones del mundo, del ser humano o de la religión de Israel

TM «Aclamadlo, naciones, con su pueblo» (Dt 32,43a).

LXX «Regocijaos, cielos, junto a él» (Dt 32,43a).

$\mathrm{TM}$ «El Señor, tu Dios, circuncidará tu corazón y el de tus descendientes para que ames al Señor, tu Dios, con todo tu corazón y con toda tu alma y así vivas» (Dt 30,6).

LXX «Y purificará completamente el Señor tu corazón y el corazón de tu descendencia para que ames al Señor, tu Dios, con todo tu corazón y con toda tu alma, para que sigas vivo» (Dt $30,6)$.

TM «El Señor escribió en las tablas, con la misma escritura que la primera vez, las "diez palabras" que el Señor os había proclamado en la montaña, desde el fuego, el día de la asamblea y me las dio» (Dt 10,4).

LXX «Y escribió en las tablas de acuerdo con el primer escrito las diez frases que os dijo el Señor en la montaña desde en medio del fuego y me las dio el Señor» (Dt 10,4).

- En los antiantropomorfismos ${ }^{79}$, con los que, en opinión de algunos autores, se evita que Dios sea sujeto de determinadas acciones:

TM «No tomarás el nombre del Señor, tu Dios, en falso, porque no dejará impune el Señor a quien pronuncie su nombre en falso» (Dt 5,11).

LXX «No tomarás el nombre del Señor, tu Dios, en vano» (Dt $5,11)$.

TM «El Señor se irritó contra mí por culpa vuestra y no me escuchó. Y me dijo el Señor: “¡Basta ya! No vuelvas a hablarme de este asunto"»(Dt 3,26).

LXX «Y me despreció el Señor por vuestra culpa y no me escuchó. Y me dijo el Señor: "Ya es suficiente. No sigas más diciendo esto"»(Dt 3,26).

TM «Cuando el Altísimo daba a cada pueblo su heredad y distribuía a los hijos de Adán, trazando las fronteras de las naciones, según el número de los hijos de Israel» (Dt 17,8).

${ }^{79}$ Se trata de una cuestión bastante discutida entre los autores; Wittstruck cree que se trata de una cuestión que se percibe en el Deuteronomio, no solo en los acentos teológicos del mismo; cfr. Thorne Wittstruck, "The so-called anti-anthropomorphisms in the Greek text of Deuteronomy", Catholic Biblical Quarterly 38 (1976): 29-34. 
LXX «Cuando el Altísimo daba a cada pueblo su heredad y distribuía a los hijos de Adán, trazando las fronteras de las naciones, según el número de los hijos de Dios» (Dt 17,8).

TM «Para Benjamín dijo: "Predilecto del Señor, morará seguro junto a él, el Altísimo lo protegerá continuamente y él morará entre sus hombros"»(Dt 33,12).

LXX «Para Benjamín dijo: "Predilecto del Señor, morará seguro junto a él, y Dios lo protegerá continuamente y él morará entre sus hombros" »(Dt 33,12).

- En la ausencia a cualquier referencia a la existencia de un rey en Israel, porque el único rey en Israel es Dios.

TM «Cuando entres en la tierra que el Señor, tu Dios, te va a dar, la tomes en posesión y habites en ella, si dices: "Voy a poner sobre mí un rey como todas las naciones que me rodean", podrás poner sobre ti un rey que elija el Señor, tu Dios. De entre tus hermanos, pondrás un rey sobre ti; no pondrás sobre ti un extranjero que no sea hermano tuyo» (Dt 17,14-16).

LXX «Y cuando hayas entrado en la tierra que el Señor Dios te da, la hayas heredado y te hayas asentado en ellas, dirás: "Pondré sobre mí un jefe, como los restantes pueblos que están alrededor de mí». Debes poner sobre ti un juez que haya elegido el Señor Dios. A uno de tus hermanos lo pondrás sobre ti mismo como juez. No podrás poner sobre ti mismo un hombre extranjero porque no es tu hermano» (Dt 17,14-15).

$\mathrm{TM}$ «Cuando se siente sobre su trono real, se hará escribir en un libro una copia de esta ley que conservan los sacerdotes levitas. La tendrá consigo y la leerá todos los días de su vida, para que aprenda a temer al Señor, su Dios, observando todas las palabras de esta ley y todos estos mandatos para cumplirlos» (Dt 17,18-19).

LXX «Y ocurrirá que, cuando esté sentado en su asiento de poder, escribirá para sí mismo esta segunda ley en un libro junto a los sacerdotes de los levitas; estará con él, y lo leerá todos los días de su vida, para aprender a temer al Señor su Dios, para guardar todos estos mandatos y estos preceptos, y para cumplirlos» (Dt 17,18-19). 
- En los acentos más propios de la teología deuteronomista ${ }^{80}$.

MT «[...] buscaréis el lugar que el Señor vuestro Dios eligiere de entre todas vuestras tribus para poner allí su nombre y morar en él, e iréis allí» (Dt 12,5).

LXX «[...] buscaréis el lugar que el Señor vuestro Dios eligiere de entre todas vuestras tribus para poner allí su nombre» (Dt $12,5)^{81}$.

TM «Las cosas sagradas que tengas y tus ofrendas votivas tómalas y llévalas al lugar que haya elegido el Señor» (Dt 12,26).

LXX «Las cosas sagradas que tengas y tus ofrendas voticas tómalas y llévalas al lugar que haya elegido el Señor para que allí se invoque su nombre» (Dt 12,26).

$\mathrm{TM}$ «Si te resulta demasiado difícil juzgar en caso de homicidio, de litigio o de lesiones - casos litigiosos en tus ciudades-, te levantarás y subirás a lugar que elija el Señor tu Dios» (Dt 17,8).

LXX «Si te resulta demasiado difícil juzgar en caso de homicidio, de litigio o de lesiones -casos litigiosos en tus ciudades-, te levantarás y subirás a lugar que elija el Señor tu Dios para que se invoque allí su nombre» (Dt 17,8).

Ahora bien, en conjunto, la versión griega del Deuteronomio es bastante conservadora; más atenta al texto original que en otros textos del Pentateuco, por ejemplo, el libro del Génesis.

Por otra parte, si comparamos los fragmentos más antiguos del Deuteronomio griego que se conservan: Papiro Rylands gr. 458; Papiro Fouad 256 (50 a. C.), que conserva extractos de Gn 7 y 38, y de Dt 11, y 31-33, y los papiros Chester Beatty (s. II d. C.), que contienen fragmentos de Números y Deuteronomio, podemos afirmar que están más próximos al Códice Alejandrino que al Sinaítico y, por tanto, que este conserva una versión más moderna de la versión griega ${ }^{82}$.

80 Léo Laberge, "Le lieu que YHWH a choisi pour y mettre son Nom (TM, LXX, Vg et Targums): Contribution à la critique textuelle d'une formule deutéronomiste", Estudios Bíblicos vol. 43 (1985): 209-236.

81 El cambio se percibe también, perfectamente, en Ex 29,45:

TM «Moraré en medio de los hijos de Israel y seré su Dios».

LXX «Seré invocado entre los hijos de Israel y seré su Dios».

82 George Howard, "The Oldest Greek Text of Deuteronomy", Hebrew Union College Annual vol. 42 (1971): 125-131. 


\section{LA IDENTIDAD DE ISRAEL FRAGUADA EN EL PENTATEUCO}

Y por último, ¿qué podemos aprender, entonces, de esa identidad fraguada en el Deuteronomio y encerrada en los muros del Pentateuco?

Moshe Weinfeld, uno de los autores que más ha estudiado el Deuteronomio, explica que la religión de Israel nunca volvió a ser la misma tras la reflexión teológica que hoy encontramos en este libro, porque los distintos autores que a lo largo del tiempo trabajaron en su composición, hicieron de él una encrucijada de tradiciones que incorporó cambios fundamentales en las creencias, el culto, los valores y la organización social, contribuyendo así a la definición de la identidad judía.

Pero hemos de tener cuidado, porque el hogar natural de cualquier espacio de definición de identidad constituye siempre un «campo de batalla» que se activa cada vez que los individuos o los grupos, confrontados con el diferente, experimentan una crisis de pertenencia y el Deuteronomio no escapa a ese peligro.

Efectivamente, el Deuteronomio muestra su lado más oscuro cuando establece el modo de proteger la identidad de Israel no solo frente al diferente, que en el texto son «los pueblos que el Señor te entregue como herencia» (Dt 20,16); sino también frente a quien, reclamando la misma identidad israelita, se aparta de las marcas identitarias señaladas en el libro.

«Si aun tu propio hermano, tu hijo o tu hija, tu esposa amada o tu más íntimo amigo, te empuja en secreto a dar culto a otros dioses que ni tú ni tus padres conocisteis, como son los dioses de los pueblos que, cercanos o lejanos, os rodean de un extremo al otro de la tierra, 8 no te sometas a sus deseos ni le hagas caso. Ni siquiera tengas compasión de él: no le tengas lástima ni lo encubras. Al contrario, mátalo. Y tú serás el primero en levantar la mano contra él, y después de ti hará lo mismo todo el pueblo. Apedréalo hasta que muera, por haber querido apartarte del Señor tu Dios, que te sacó de Egipto, donde eras esclavo. De esta manera todo Israel lo sabrá, y tendrá miedo de volver a cometer una maldad como esta» (Dt 13,6-11).

En ese momento, el discurso del libro olvida la condición ilustrada y alfabetizada de su identidad, e impone la identidad comunitaria, con lo que tiene de hipotética, histórica o relativa, a cualquier otro valor humano y, así, se convierte en una identidad impositiva, o, como hace 
notar Thomas Römer, en un segregacionismo violento y espeluznante ${ }^{83}$ que convierte la identidad en «asesina», porque «reduce la identidad a la pertenencia a una sola cosa, instala a los hombres en una actitud parcial, sectaria, intolerante, dominadora, a veces suicida, y los transforma a menudo en gentes que matan o en partidarios de los que lo hacen ${ }^{84}$.

Quizás, precisamente en este tiempo de identidades conflictivas, viene bien hacer memoria de algunas cosas que hemos destacado en este trabajo:

Conviene recordar cómo el Deuteronomio estremeció el corazón del rey Josías, que comprendió que la desorientación y la crisis de Judá tenían que ver con el olvido del libro.

Conviene hacer memoria también de que cuando los fariseos preguntan a Jesús ¿cuál es el mandamiento principal de la ley?, Él les responde con una síntesis de lo mejor del Deuteronomio, la primacía de Dios en el rostro del otro "Amarás al Señor tu Dios con todo tu corazón, con toda tu alma, con todas tus fuerzas», y "amarás a tu prójimo como a ti mismo» (Mt 22,37-39).

Conviene no olvidar que la posición del Deuteronomio en el Pentateuco le confiere un el carácter liminar y fronterizo, porque sabe «que las fronteras, por muy altas que sean las murallas chinas, nunca impiden ignorar lo existente más allá, ni envolverlo en la indiferencia» ${ }^{85}$.

Y, por último, quizás no sea mala cosa recordar que, gracias a la aportación del Deuteronomio, Israel tomó la decisión de editar una Torá, y, así, convirtió el libro, la biblioteca, en impronta formativa del pueblo, y hasta nuestros días:

«[...] sólo los libros son sagrados; nada más. Ni templo, ni reliquia, ni dinastía apostólica; sólo los libros quedaron en pie. Así que cuando corrías para salvar la vida, huyendo de la masacre y del progromo, de la quema de hogares y sinagogas, eran los niños y los libros lo que te llevabas. Los libros y los niños» ${ }^{86}$.

83 Thomas Römer, “'Par amour et pour garder le serment fait à vos pères' (Dt 7,8). Les notions de peuple de Yhwh et d'élection dans le livre du Deutéronome et la tradition deutéronomiste" en "Vous serez mon peuple et je serai votre Dieu». Réalisations et promesse, dir. François Lestang, Philippe Abadie, Marie-Hélène Robert, y Marc Rastoin (Namur/Paris: Lessius, 2016).

84 Amin Maalouf, Identidades asesinas (Madrid: Alianza Editorial, 2001), 38.

85 José Luis Sampedro, Desde la frontera (Madrid: Real Academia Española, 1991), 18.

86 Amos Oz y Fania Oz, Los judíos y las palabras (Madrid: Siruela, 2004), 42. 


\section{BIBLIOGRAFÍA}

Albertz, Rainer. Historia de la religión de Israel en los tiempos del Antiguo Testamento. Vol. 1, De los comienzos hasta el final de la monarquía. Trotta: Madrid, 1999.

Altmann, Peter. Festive Meals in Ancient Israel Deuteronomy's Identity Politics in Their Ancient Near Eastern Context. Berlin: W. De Gruyter, 2011. https://doi.org/10.1515/9783110255379

Arnold, Bill T. "Deuteronomy as the Ipsissima Vox of Moses". Journal of Theological Interpretation 4, n. ${ }^{\circ} 1$ (2010): 53-74.

Berge, Kàre. "Literacy, utopia and memory: is there a public teaching in Deuteronomy?". The Journal of Hebrew Scriptures 12 (2012), consulta 12 de septiembre de 2018. https://doi.org/10.5508/jhs.2012.v12.a3

Block, Daniel I. "How Many is God? An Investigation into the Meaning of Deuteronomy 6:4-5". Journal of the Evangelical Theological Society 47 (2004): 193-212.

Carr, David M., ed. Holy Resilience: The Bible's Traumatic Origins. New Haven: Yale University Press, 2014. https://doi.org/10.12987/ yale/9780300204568.001.0001

Clements, Ronald Ernest, R. W. L. Moberley, and G. J. McConville. "A dialogue with Gordon McConville on Deuteronomy". Scottish Journal of Theology 56, n. 4 (2003): 508-531. https://doi.org/10.1017/ S0036930603211212

Collins, John J. The Invention of Judaism: Torah and Jewish Identity from Deuteronomy to Paul. The Taubman lectures in Jewish studies 7. Berkeley: University of California Press, 2017. https://doi. org/10.1525/california/9780520294110.001.0001

Craigie, Peter G. The Book of Deuteronomy. New International Commentary on the Old Testament. London: Hodder and Stoughton, 1976.

Crouch, Carly Lorraine. The Making of Israel. Cultural Diversity in the Southern Levant and the Formation of Ethnic Identity in Deuteronomy. Supplements to Vetus Testamentum 162. Leiden: Leiden, 2016.

- . "The threat to Israel's identity in Deuteronomy: Mesopotamian or Levantine?". Zeitschrift für die Alttestamentliche Wissenschaft 124, n. ${ }^{\circ} 4$ (2012): 541-554.

Díaz Herrera, Pablo. "Deuteronomio: narración o discurso. La forma y la estructura del libro”. Reseña Bíblica 96 (2007/IV): 13-21. 
Dogniez, Cécile y Marguerite Harl. La Bible d'Alexandrie. Le Deutéronome. Introduction et notes. Paris: Éditions du Cerf, 1992.

Driver, Samuel R. A critical and exegetical commentary on Deuteronomy. Edinburgh: T \& T Clark, 1896.

Duncan, Julie A. "Excerpted texts of 'Deuteronomy' at Qumran”. Revue de Qumrân 69 (1997): 43-62.

-."Deuteronomy". En Encyclopedia of the Dead Sea Scrolls, vol I, editado por Lawrence H. Schiffman y James C. VanderKam, 199-202. Londres: Oxford University Press, 2000.

Fernández, Marcos Natalio y M. ${ }^{a}$ Victoria Spottorno, dirs. La Biblia griega Septuaginta. Vol. 1, El Pentateuco. Salamanca: Sígueme, 2008.

García, Florentino. "Les manuscrits du Désert de Juda et le Deutéronome". En Studies in Deuteronomy, in Honour of C. J. Labuschagne, dirigido por Casper J. Labuschagne y Florentino García Martínez, Supplements to Vetus Testamentum 53, 63-82. Leiden: Brill, 1994.

García, Félix. "La muerte de Moisés, la sucesión de Josué y la Escritura de la Tôrah (Dt 31-34)". En The future of the Deuteronomistic History, dirigido por Thomas Römer, Bibliotheca Ephemeridum Theologicarum Lovaniensium 147, 85-99. Leuven: Leuven University Press, 2000.

-. "Deuteronomio 31, el Pentateuco y la Historia Deuteronomista". En Deuteronomy and Deuteronomic Literature. Festschrift C. H. W. Brekelmans, dirigido por Lust J. Vervenne, Bibliotheca Ephemeridum Theologicarum Lovaniensium 133, 71-85. Leuven: Peeters, 1997.

—. "'El único pueblo sabio e inteligente’: Dios, ley y pueblo en la estrategia religiosa del Deuteronomio (Dt 4,5-8; 6,4-9; 30,15-20)". Ricerche Storico Bibliche 15, n. 1 (2003): 9-24.

Giuntoli, Federico y Konrad Schmid. The post-priestly Pentateuch: new perspectives on its redactional development and theological profiles, Forschungen zum Alten Testament 101. Tübingen: Mohr Siebeck, 2015.

Granados, Carlos. Deuteronomio. Madrid: Biblioteca de Autores Cristianos, 2017.

Greenspahn, Frederick E. "Deuteronomy and Centralization". Vetus Testamentum 64, n. ${ }^{\circ} 2$ (2014): 227-235.

Haber, Susan. "God, Israel and covenant: unity in the Book of Deuteronomy”. European Judaism 32, n. ${ }^{\circ} 1$ (1999): 132-141.

Huggins, Marvin. "Secularization in the Centralization of the Cult in Deuteronomy". Master of Divinity Thesis, Concordia Seminary St. Louis 1969. Consulta 22 de junio de 2018. http://scholar.csl.edu/mdiv/59 
Howard, George. "The Oldest Greek Text of Deuteronomy”. Hebrew Union College Annual vol. 42 (1971): 125-131.

Hurowitz, Victor. "From storm God to abstract being: how the deity became more distant from Exodus to Deuteronomy”. Bible Review 14, n. ${ }^{\circ} 5$ (1998): 40-47.

Kermode, Frank. El Sentido de un Final: Estudios Sobre la Teoría de la

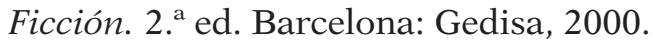

Kitchen, Kenneth A. On the Reliability of the Old Testament. Eerdmans: Grand Rapids, 2003.

Kratz, Reinhard Gregor. "The idea of cultic centralization and its supposed ancient Near Eastern analogies”. En One God - One Cult - One Nation, editado por Reinhard G. Kratz y Hermann Spieckermann, Beihefte zur Zeitschrift für die alttestamentliche Wissenschaft 405, 119-144. Berlin: De Gruyter, 2010. https://doi.org/10.1515/9783110223583.119

Laberge, Léo. "Le lieu que YHWH a choisi pour y mettre son Nom (TM, LXX, Vg et Targums): Contribution à la critique textuelle d'une formule deutéronomiste”. Estudios Bíblicos vol. 43 (1985): 209-236.

León, Juan Luis de. Deuteronomio. Bilbao: Desclée de Brouwer, 2009.

Lohfink, Norbert. "Distribution of the Functions of Power: The Laws Concerning Public Offices in Deuteronomy 16:18 - 18:22”. En A Song of Power and the Power of Song: Essays on the Book of Deuteronomy, dirigido por Duane L. Christensen, Sources for Biblical and Theological Study 3, 336-352. Winona Lake: Eisenbrauns, 1993.

López, Emilio. "El libro del Deuteronomio: puerta abierta, perno entre dos mundos”. Reseña Bíblica 96 (2017): 6-7.

Maalouf, Amin. Identidades asesinas. Madrid: Alianza Editorial, 2001.

Merrill, Eugene H. Deuteronomy. New American Commentary 4. Nashville: Broadman \& Holman, 1994.

Moyise, Steve y Maarten J. J. Menken, eds. Deuteronomy in the New Testament: The New Testament and the Scriptures of Israel. Journal for the Study of the New Testament Supplement Series 358. New York: T\&T Clark, 2008.

Nicholson, Ernest. Deuteronomy and the Judaean Diaspora. Oxford: Oxford University Press, 2004.

Nelson, Richard D. “A Response To Thomas C. Römer, The So-Called Deuteronomistic History”. En "In Conversation with Thomas Römer, The So Called Deuteronomistic History". The Journal of Hebrew Scriptures vol. 9 (2009). Consulta 22 de mayo de 2018. http://dx.doi. org/10.5508/jhs.2009.v9.a15 
—. Deuteronomy: a Commentary. The Old Testament Library. Louisville: Westminster John Knox Press, 2002.

- "The Centralisation Of The Cult In Deuteronomy". Vetus Testamentum 13, n. ${ }^{\circ}$ (1963): 380-389.

Nihan, Christoph. "The emergence of the Pentateuch as 'Torah"'. Religion Compass 4, n. ${ }^{\circ} 6$ (2010): 353-364.

Otto, Eckart. "Anti-Achaemenid propaganda in Deuteronomy”. En Homeland and Exile; Biblical and Ancient Near Eastern Studies in Honour of Bustenay Oded, dirigido por Gershon Galil, Mark Geller, y Alan Millard, Supplements to Vetus Testamentum 130, 547-558. Leiden: Brill, 2010. https://doi.org/10.1163/ej.9789004178892.i-648.152

-. Kontinuum und Proprium; Studien zur Sozial- und Rechtsgeschichte des Alten Orients und des Alten Testaments. Orientalia Biblica et Christiana 8. Wiesbaden: Harrassowitz, 1996.

Oz, Amos y Fania Oz. Los judíos y las palabras. Madrid: Siruela, 2004.

Pizzorno, Patricia. "No debe haber necesitado en medio de ti...' (Dt 15.4): dimensión social de la bendición en el libro del Deuteronomio". Protestantismo em Revista vol. 23 (2010): 85-91. Consulta 16 de septiembre de 2018. http://dx.doi.org/10.22351/nepp.v23i0.69

Reimer, Haroldo. "Leyes y relaciones de género - Notas sobre Éxodo 21,2-11 y Deuteronomio 15,12-18". RIBLA n. ${ }^{\circ} 37 / 3$ (2000): 116-127.

Richter, Sandra L. "The Place of the Name in Deuteronomy". Vetus Testamentum 57, n. 3 (2007): 342-366.

Römer, Thomas C. "Par amour et pour garder le serment fait à vos pères $($ Dt 7,8$)$ - Les notions de peuple de Yhwh et d'élection dans le livre du Deutéronome et la tradition deutéronomiste”. En «Vous serez mon peuple et je serai votre Dieu» (Ez 36,28): réalisations et promesse, editado por François Lestang Philippe Abadie, Marie-Hélène Robert, and Marc Rastoin, 113-134. Bruxelles: Lessius, 2016.

Römer, Thomas. "Le probleme du monothéisme biblique". Revue Biblique 124, n. ${ }^{\circ}$ (2017): 12-25.

- The Invention of God. Cambridge: Harvard University Press, 2015. https://doi.org/10.4159/9780674915732

Rose, Martin. "Deuteronomio”. En Introducción al Antiguo Testamento, editado por Thomas Römer, Jean Daniel Macchi, y Christoph Nihan, 211-230. Bilbao: Desclée de Brouwer, 2008.

Sampedro, José Luis. Desde la frontera. Madrid: Real Academia Española, 1991. 
Schmid, Konrad. "The Late Persian Formation of the Torah: Observations on Deuteronomy 34". En Judah and the Judeans in the Fourth Century B. C. E., editado por Oded Lipschits, Gary Knoppers y Rainer Albertz, 237-251. Winona Lake: Eisenbrauns, 2007.

Sonnet, Jean Pierre. The Book Within the Book: Writing in Deuteronomy. Biblical Interpretation Series 14. Leiden: Brill, 1997.

- " "The Fifth Book of the Pentateuch: Deuteronomy in Its Narrative Dynamic". Journal of Ancient Judaism 3, n. ${ }^{\circ} 2$ (2012): 197-234. https:// doi.org/10.13109/jaju.2012.3.2.197

- "Le Deutéronome et la modernité du livre". Nouvelle Revue Théologique 118, n. ${ }^{\circ} 4$ (1996): 481-496.

Tcherikover, Victor. Hellenistic civilization and the Jews. Philadelphia: The Jewish Publication Society of America, 1966.

Thompson, Deanna A. Deuteronomy: A Theological Commentary on the Bible, Belief: A Theological Commentary on the Bible. Louisville: Westminster John Knox Press, 2014.

Vang, Carsten. “The so-called 'Ur-Deuteronomium': some reflections on its content, size and age". SEE-J Hiphil 6 (2009): 1-22. Consulta 1 de septiembre de 2018, http://www.see-j.net/index.php/hiphil/article/view/40

Vogt, Peter T. "Deuteronomy: A History of Interpretation and Evangelical Responses". En Sepher Torath Mosheh. Studies in the Composition of Deuteronomy, dirigido por Daniel I. Block y Richard L. Schultz, 7-29. Peabody: Hendrickson Publisehers, 2017.

Weinfeld, Moshe. Deuteronomy and the Deuteronomic School. Winona Lake: Eisenbrauns, 1992.

—."Deuteronomy's theological revolution". Bible Review 12, n. 1 (1996): 38-41, 44-45.

Wenham, Gordon J. "Deuteronomy and the Central Sanctuary". Tyndalle Bulletin 22 (1971): 103-118.

Wevers, John William. Notes on the Greek Text of Deuteronomy. Septuagint and Cognate Studies / Society of Biblical Literature 39. Scholars Press: Atlanta (GA), 1995.

-. "The Earliest Witness to the LXX Deuteronomy". Catholic Biblical Quarterly vol. 39 (1977): 233-234.

Wittstruck, Thorne. "The so-called anti-anthropomorphisms in the Greek text of Deuteronomy". Catholic Biblical Quarterly 38 (1976): 29-34. 